\title{
A sociedade e a violência na escola: proposta de solução
}

\section{The society and the violence in school: a proposal of solution}

Rosemary Tourinho ${ }^{1}$ Maria Eleusa Montenegro ${ }^{2}$ Altair Stemler da Veiga ${ }^{3}$

1 Graduada em Letras pelo Centro Universitário de Brasília (UniCEUB).

2 Doutora em Educação pela Universidade Estadual de Campinas (UNICAMP), PósDoutora pela Universidade de Brasília (UnB) e professora do Centro Universitário de Brasília (UniCEUB).

3 Mestre em Direito Internacional Público (área Direito Espacial) pelo UniCEUB. Advogada e professora do Centro Universitário de Brasília (UniCEUB).

\section{Resumo}

O presente artigo volta-se para o estudo, a análise e a proposta de um plano de ação para lidar com o fenômeno da violência nas escolas, sobretudo nas escolas públicas de Ensino Fundamental e Médio de Santa Maria, Região Administrativa do Distrito Federal, lugar em que foi realizada uma pesquisa de diagnóstico do problema. Diante da constatação da presença da violência na escola, o artigo busca propor estratégias a serem tomadas a fim de minimizar essa realidade enfrentada por educadores. A escola não pode ignorar que os conflitos e problemas sociais existem. Consciente disso, acaba percebendo que seu trabalho é insuficiente para acabar com a violência. Sugere-se que toda a sociedade se mobilize para garantir o objetivo comum das escolas, que é a formação dos cidadãos.

Palavras-chave: Violência. Plano de ação. Estratégias.

\begin{abstract}
This article aims to the study, the analysis and the proposal of an action plan to deal with the phenomenon of violence in schools, especially public schools of elementary and high school in Santa Maria, administrative region of the Federal District, place where it was conducted a survey to diagnose the problem. Given the finding of the presence of violence in the school, the article seeks to propose strategies to be taken to minimize this reality faced by educators. The school cannot ignore that there are conflicts and social problems. Aware of this, the school realizes that its work is not enough to stop the violence. It is suggested that the entire society must be mobilized to ensure the common goal of the school, which is the formation of citizens.
\end{abstract}

Keyword: Violence. Action plan. Strategies. 


\section{Introdução}

Os pais ou responsáveis entendem que, além do conteúdo pedagógico ou do conhecimento formal, seus filhos receberão dos professores e orientadores educacionais a devida orientação para o convívio em sociedade, em um ambiente de tolerância e respeito mútuo. As escolas recebem crianças e adolescentes que já trazem conhecimentos e que se encontram em diferentes idades, o que torna inevitável o aparecimento de conflitos, condição essa que exige que os professores viabilizem estratégias necessárias para resolvê-los.

O que se vê hoje são situações em que as ações praticadas por crianças e adolescentes são imprevisíveis e inaceitáveis dentro do contexto escolar. O que antes era apenas um simples conflito passa a ser chamado de violência escolar dos mais variados tipos, quais sejam, violência física, psicológica ou sexual.

As manifestações de violência e de agressividade nas escolas dos dias atuais, de acordo com Fante (2005, p. 168), são um fenômeno social complexo e difícil de entender, porque atingem a sociedade como um todo, afetando diretamente as crianças de todas as faixas etárias. Sabe-se que esse fenômeno é resultante de fatores tanto internos como externos à escola, que são caracterizados pelos tipos de interações sociais, familiares, socioeducacionais e pelos comportamentos agressivos nas relações interpessoais.

Infelizmente, o que antes eram apenas conflitos corriqueiros passou a ser um tipo de problema antes ocorrido somente fora dos muros escolares. Por isso mesmo, está-se diante de um assunto complexo, o qual ainda gera muitas dúvidas sobre como capacitar os educadores para lidar com o fenômeno da violência nas escolas.

O objetivo deste artigo é apresentar uma propostas de solução para conter a violência, primeiramente, em uma escola de Ensino Fundamental na região administrativa de Santa Maria, no Distrito Federal, onde foi feita uma pesquisa de cunho qualitativo analisando os diferentes tipos de violência ali existentes, tomando como referência algumas categorias tais como: as formas de violência, as suas causas, as suas consequências, as medidas de prevenção e de diminuição dessa violência, o papel da escola, a participação dos pais e o engajamento da comunidade e do Estado, assim como a preparação para lidar com a violência.
As propostas apresentadas têm como objetivo contribuir para o processo de superação da violência na escola e na comunidade.

Acredita-se, assim, que os resultados deste trabalho, poderão sugerir alternativas de soluções que podem ser aplicadas em escolas de outras regiões do Distrito Federal.

\section{Fase preparatória das ações}

\subsection{Diagnóstico}

Violência, segundo Abramovay (2003 apud FANTE, 2005), são manifestações que se referem a explicações de ordem socioeconômica, ao agravamento de exclusões sociais, raciais e de gênero, à perda de referencial entre os jovens, ao surgimento de "galeras", "gangues", "tráfico de drogas", desestruturação familiar, à perda de espaços de sociabilidade.

De acordo com Priotto (2008 apud PRIOTTO; BONETI, 2009) os tipos de violência, podem expressarse das seguintes maneiras:

Violência física: de um indivíduo ou grupo contra a integridade de outro(s) ou de grupo(s) e também contra si mesmo, abrangendo desde os suicídios, espancamentos de vários tipos, roubos, assaltos, homicídios, além de diversas formas de agressões sexuais;

Agressão física: homicídios, estupros, ferimentos, roubos, porte de armas que ferem, sangram e matam;

Violência simbólica verbal: abuso do poder, baseado no consentimento que se estabelece e se impõe mediante o uso de símbolos de autoridade;

Violência simbólica institucional: marginalização, discriminação e práticas de assujeitamento usadas por instituições diversas que instrumentalizam estratégias de poder;

Violência verbal: incivilidades (pressão psicológica), humilhações, palavras grosseiras, desrespeito, intimidações ou bullying.

De acordo com a pesquisa de cunho qualitativo realizada na escola da região administrativa de Santa Maria, verificou-se que a violência não é assim tão alarmante; por isso mesmo, precisa-se agir de forma preventiva para que não se torne um problema mais sério no futuro. 
Participaram da pesquisa dois professores, uma diretora, um orientador pedagógico, uma representante da comunidade, um representante de uma ONG e um representante do Conselho Tutelar, sendo ao todo três mulheres e quatro homens, todos moradores da região pesquisada.

As principais causas de violência presentes na escola pesquisada, de acordo com levantamento feito foram: a falta de investimento do Estado na educação, o ambiente familiar violento, o meio social, a pobreza, o alcoolismo, as drogas e o preconceito em geral.

Quando entrevistados, os participantes da pesquisa relataram que o bullying, as ameaças e as agressões verbais são manifestações de violência mais frequentes na escola, conforme atesta o comentário de um dos professores entrevistados:

Entre alunos, as manifestações de violência são por meio do bullying e brigas por motivos fúteis. Contra os professores os alunos fazem ameaças, intimidações e vias de fato (raramente) provocadas por alunos e pais. (Relato de professor entrevistado).

Quanto às consequências da violência foram citadas a evasão escolar, a descrença nas instituições e nas pessoas, a desmotivação, a agressividade dentro e fora da escola e a desvalorização da escola e dos professores. Também foram mencionados a falta de identidade, o baixo rendimento, a infrequência e os vícios.

Quando perguntados sobre as medidas de prevenção, os entrevistados apresentaram variados projetos que já se encontravam em desenvolvimento. Esses projetos não estão, diretamente, ligados à violência, mas os professores desenvolvem o tema com os alunos em sala de aula.

Os professores acreditam que atividades relacionadas ao esporte, jogos lúdicos e passeios podem contribuir para a prevenção da violência, porém esses profissionais necessitam de mais motivação, porque têm uma sobrecarga, não só de atividades, mas também em relação à responsabilidade social com os alunos.

Quanto à participação dos pais e responsáveis, a diretora da escola pesquisada relatou que eles participam, minimamente, da vida escolar dos filhos e só comparecem à escola quando são chamados pela direção. Nota-se, por essa ótica, que a ausência da família é um fator fundamental no contexto de violência escolar.
Os professores pesquisados já presenciaram atitudes de violência e também já foram vítimas de alguns tipos de violência, como agressões verbais e ameaças contra a sua integridade física.

De acordo com o representante da comunidade, o mundo contemporâneo contribui para essa situação de violência por meio de seus novos modelos de família e de ações, mas é difícil apontar um responsável, sendo que a família e o Estado também são responsáveis por tal situação.

A questão da violência nas escolas públicas do Distrito Federal envolve diversos fatores e constitui algo que vem tomando dimensões desproporcionais, sendo necessárias providências, com vistas a minorar tal situação. Os dados são alarmantes. Há um número considerável de adolescentes que se encontram fora das escolas e, por sua vez, envolvidos com a violência e com a criminalidade.

Dados encontrados na pesquisa demonstraram que uma parte mínima dos professores estão preparados, porque, com as experiências do dia-a-dia, acabam aprendendo a contornar alguns problemas que surgem. Alguns professores destacaram que não foram preparados para lidar com esse tipo de situação. Segundo o relato de um dos professores: "na formação acadêmica falta muito o contato com a escola real, o aluno real e sobra o ideal".

Constatou-se, em alguns depoimentos, o medo dos professores de lidar com determinadas situações, quando acontecem nos arredores da escola, em especial, os problemas com o tráfico de entorpecentes. De acordo com matéria da Revista Veja (1996, p. 54), uma das principais explicações para a indisciplina na escola é a falta de educação e limites em casa:

[...] alunos indisciplinados e mal educados atormentam professores, e estes não apresentam condições para "controlar a bagunça que come solta dentro da sala de aula". E o que é pior: não bastassem as conversinhas, os risinhos, as guerrinhas de papel, o respeito pela figura do professor passou a ser tão raro como uma nota 10 em redação.

Os professores, realmente, não foram preparados para lidar com a violência escolar e acabam por utilizar de suas experiências para contornar as situações que envolvem violência.

\subsection{A comunidade interna e a comunidade externa}

Diagnosticados os fatores que causam a violência na escola pesquisada e suas consequências, buscaram-se 
neste trabalho alternativas educacionais eficazes para que se possa minimizar o que foi diagnosticado.

Para tanto, na primeira parte do plano de ação, deve-se viabilizar uma série de ações para sensibilizar os diversos segmentos do contexto escolar interno e externo, ou seja, coordenadores, professores, funcionários, pais ou responsáveis. Em seguida, adotar-se-ão outras ações, essas desenvolvidas juntamente com os alunos, para que haja assim, o envolvimento de toda a comunidade escolar tanto a interna como a externa.

\section{Plano de ação para prevenção e redução da violência}

No Quadro 1 são estabelecidos o público-alvo, as metas, os objetivos, as diretrizes para as ações, as propostas de ações, as ações estratégicas, os responsáveis pelo desenvolvimento do plano de ação, a avaliação do plano e o período da ação.

Quadro 1 - Plano de ação para prevenção e redução da violência

\section{População a ser beneficiada: público alvo}

Alunos, professores e pais da escola pública de Santa Maria no Distrito Federal.

Meta

Prevenir e reduzir, de forma viável, os problemas de violência e de indisciplina verificados na escola.

Objetivo geral

Promover ações que levem à prevenção das formas de violência que existem na escola ou que possam surgir.

Objetivos específicos

- Sensibilizar coordenadores, professores e funcionários;

- Integrar escola e sociedade;

- Promover encontros para atividades com os professores dos diferentes turnos;

- Realizar atividades pedagógicas com a participação dos alunos;

- Estimular e divulgar os trabalhos a serem desenvolvidos pelos alunos;

- Buscar apoio significativo de pais e responsáveis por meio de palestras, jogos, oficinas de arte e lazer, e de outras atividades extras de acordo com o interesse da comunidade e

- Apresentar atividades como teatro, festivais de música, campeonatos esportivos, gincanas, caminhadas e outras programações que possam contribuir para a educação e o envolvimento dos alunos. Todas as atividades deverão estar relacionadas ao tema violência.

\section{Diretrizes para as ações}

Este plano contempla diretrizes para que possam ser desenvolvidas as ações propostas:

- O ponto principal deve ser a violência na escola pública do Distrito Federal objeto de análise e as medidas que devem ser tomadas para atingir as finalidades do plano, quais sejam, prevenção e combate.

- A base de todas as ações do plano deve ser a garantia da presença dos participantes e daqueles que buscam um caminho para atingir o objetivo do projeto.

- As ações do plano devem ser realizadas de tal forma que levem os participantes a se integrarem para alcance do objetivo do projeto.

- O plano de ação deve ser acompanhado e fiscalizado a partir do momento em que for implantado, para que não haja descontinuidade e para que as ações propostas sejam levadas a termo.

\section{Propostas de ações}

O plano adotará as prioridades, as ações e as etapas a serem seguidas para o seu desenvolvimento. As medidas a serem tomadas são delineadas a seguir:

- Preparação dos professores: por meio de cursos para desenvolvimento de suas tarefas;

- Preparação dos alunos: por meio de projetos socioeducativos, tais como esporte, educação artística, teatro e música;

- Preparação dos pais de alunos: por via de projetos que abranjam palestras, civilidade, etiqueta, culinária e educação e

- Participação dos pais na vida escolar: a) projetos que possam atrair os alunos para a escola com o apoio dos pais, b) acompanhamento por parte dos pais do desenvolvimento escolar dos filhos, c) medidas educativas para facilitar o diálogo entre pais e alunos. 


\section{Ações estratégicas}

Articulação entre a direção da escola, os professores, os alunos e os pais, visando estabelecer um primeiro contato para viabilização do projeto:

- Visita à escola pública de Santa Maria para primeiros contatos com a direção da escola (primeiro mês do desenvolvimento do projeto);

- Reuniões com a direção da escola e os professores para delinear os pontos fundamentais a ser desenvolvidos em face dos tipos de violência encontrados na escola. Neste período deverão ser ministradas palestras por profissionais que possam levar seu conhecimento sobre o tema aos professores e à direção (segundo mês do desenvolvimento do projeto);

- Reuniões com os pais dos alunos com os professores, visando à análise dos problemas por eles apresentados no diagnóstico, em face das situações encontradas no binómio casa/escola. Neste período também acontecerão palestras com profissionais (terceiro mês do desenvolvimento do projeto) e

- Depois de realizadas todas as reuniões para a organização do processo, serão estipulados períodos para a realização das atividades a ser realizadas (campeonatos esportivos, concursos de redações, campeonatos de dança e música entre outras). Todas essas atividades, como foi mencionado, deverão abordar ou estar relacionadas ao tema violência.

\section{Responsável}

Professora. Dra. Maria Eleusa Montenegro

Líder do grupo de pesquisa Prática Pedagógica e Formação do Professor.

Nome da pesquisa "A sociedade e a violência na escola: diagnose - proposta de solução - ação".

Avaliação

A pretensão deste plano é tentar transformar, pelo menos, em parte a realidade observada, fazendo com que a participação não só do meio escolar, mas também da sociedade, possa demonstrar o quanto é preocupante a situação atual de violência na escola.

A avaliação será contínua e processual por meio do acompanhamento e da observação do cotidiano escolar: análise dos registros dos Serviços de Orientação Educacional, análise da atuação da prática docente e discente e análise da participação dos pais e da comunidade.

Ao final do trabalho deverá ser aplicado um questionário aos participantes da pesquisa, a fim de verificar os resultados do plano de ação desenvolvido.

Período

Este plano é elaborado para ser executado no período de 01 ano.

\section{Possíveis desdobramentos da pesquisa}

Entre os possíveis desdobramentos da pesquisa aqui apresentada, podemos citar os seguintes:

Tratativas com o Governo do Distrito Federal (GDF), buscando ações para a melhoria da situação de violência em outras escolas de Santa Maria, considerando-se o alto índice de evasão escolar por conta da violência, quais sejam:

a) Reunião com o GDF e a Secretaria de Educação, buscando a estatística da evasão escolar em Santa Maria e

b) Discussão com o GDF quais seriam as tratativas para a diminuição da violência nas escolas em questão.

Proposta de trabalho nessas escolas públicas (com a participação da sociedade), em vista de possíveis convênios entre o GDF e empresas particulares, delineados a seguir: a) Levantamento das necessidades tanto físicas, quanto educacionais, em conjunto com a direção da escola e os professores e

b) Contatos com empresas que possam firmar convênios para a reabilitação das escolas e, ainda, fornecer material didático e alimentação.

Interação do GDF, por via das suas Secretarias de Cultura e de Esportes ou outras organizações, para o desenvolvimento de projetos socioeducativos, como se apresentam:

a) Reunião com a Secretaria de Cultura com o objetivo de montar projetos nas áreas de artes e

b) Reunião com a Secretaria de Esportes para viabilizar projetos visando à prática de diversas modalidades de esportes. Nesse período será comunicada a pretensão de se fazer uma caminhada ou marcha contra a violência nas escolas, envolvendo escolas da região, professores, alunos, diretores, pais, e também contando 
com a sociedade, polícia militar e bombeiros.

Determinação das formas de controle do processo e avaliação dos resultados, que podem ser:

a) Reuniões com os órgãos envolvidos;

b) Entrevistas com os atores indicados;

c) Levantamento de situações a serem discutidas e finalizadas;

d) Apresentação da estatística dos assuntos levantados e

e) Finalização e apresentação dos projetos.

Após todas as reuniões para viabilização do plano de ação, acontecerão as demais atividades, quais sejam:

a) Realização de palestras que tratem sobre a não violência e a disciplina;

b) Abordagem do assunto "disciplina escolar" em sala de aula utilizando o Regimento Escolar;

c) Elaboração de contrato pedagógico (acordos e contratos) com os alunos;

d) Apresentação de fotos da escola para que se perceba que o espaço escolar é um ambiente que exige atitude responsável de todos;

e) Reuniões com pais para discussão sobre a formação das crianças e dos adolescentes;

f) Reuniões para apresentar aos pais o Regimento Escolar e esclarecer os direitos e deveres estabelecidos no Estatuto da Criança e do Adolescente (ECA); g) Reuniões específicas de pais para orientar e esclarecer sobre o comportamento e desempenho das turmas com levantamento das dúvidas e sugestões para escola e para a turma;

h) Encontros com professores para orientações em grupo ou individuais e

i) Exposição de cartazes com o tema abordado.

Espera-se, com o desenvolvimento deste projeto, contribuir para o combate à violência na escola cenário da pesquisa, bem como em outras escolas de Santa Maria e, quiçá, em outras escolas do Distrito Federal.

Prevê-se que os resultados deste trabalho sejam apresentados em eventos científicos nacionais e internacionais e publicados em periódicos.

\section{Referências}

ABRAMOVAY, M.; RUA, M. G. Violência nas escolas. Brasília: UNESCO, 2003.

FANTE, C. Fenômeno bullying: como prevenir a violência nas escolas e educar para a paz. 2. ed. São Paulo: Verus, 2005.

PRIOTTO, E. P.; BONETI, L. W. Violência escolar: na escola, da escola e contra a escola. Revista Diálogo Educacional, Curitiba, v. 9, n. 26, p. 161-179, jan./ abr. 2009.

UNIDOS NA BAGUNÇA. Revista Veja, São Paulo, n. 22, p. 54-56, 29 de maio de 1996. 